\title{
Cerebral Angiography in lateral decubitus
}

\begin{abstract}
Transradial approach is used routinely for performing coronary angiography in multiple centers worldwide. In our center is the first choice of approach for cerebral angiographies from two years ago. The aim of this paper is to present a case of cerebral angiography performed in a lateral decubitus position in a patient with a history of recurrent bleeding AVM at supine decubitus. Cervical and brain vessels angiography was performed in lateral decubitus position through a right radial artery puncture. This case shows the utility of this approach in cases of supine decubitus contraindication.
\end{abstract}

Volume 8 Issue 2 - 2018

\author{
Javier Goland, Gustavo Doroszuk, Fernando \\ Alvarez \\ University UBA, Hospital El Cruce, Argentina
}

Correspondence: Javier Goland, University UBA, 2236 CABA, Argentina,Email javiergoland@gmal.com

Received: March 28, 2018| Published: April 27, 2018

\section{Introduction}

Cerebral angiography catheterization is the gold standart method for the study of brain vascularization. Femoral artery approach is the most common one used for this studies, however there are certain situations in which it is not possible to approach through this artery because of stenosis or aneurysms of iliac or aorta arteries secondary to atheromatosis. Campeau published in 1989 the first series of transradial approach for selective catheterization of coronary arteries. ${ }^{1}$ From there, it has been widely developed coronary experience first and then this way cerebral angiography. ${ }^{2,3}$ This approach is associated with a lower incidence of complications associated with puncture, more comfort for patients and shorter time of stay after the study. ${ }^{4-6}$ Alternative approaches to femoral puncture are brachial, cervical carotid andradial approaches. ${ }^{7}$ Radial approach is the only one that allows the study in a different position to supine. However there are no cases reported of angiography in lateral decubitus position.

\section{Case report}

Female patient, 30 years old with a history of right occipital vascular malformation partially treated in another center. The patient was derived to performcervical and cerebral angiography. The patient had a history of heavy bleeding in supine position because of the venous hypertension. Decubitus with no bleedings of the lesion were ventral and lateral one which were used for sleeping since two years before the study. Given the impossibility of supine and having the experience of transradial angiography, we decided to perform the usual procedure but in a left lateral decubitus with her right arm placed at the body side. A superficial sedation was perform with Midazolam (1mg). The patient was placed on the table in a left lateral decubitus with his right arm in the supine position on the right side edge of the body and the hand attached with a bandage (Figure 1). The procedure was performed through a $5 \mathrm{~F}$ radial sheath (Merit Medical Systems, Utah, USA), once in the lumen of the artery we instilled $5 \mathrm{ml}$ Nitroglycerin (200ug/mL) and then Heparin 5000IU. Catheterization was performed with Simmons II catheter placing the bow team in position perpendicular to the patient and both carotid arteries were studied (Figure 2). The insight gained by the team with the patient in this position and the arch located perpendicular to it is equal to the supine position so there was no difficulty to perform the required study (Figure 3). The study was performed in 30minutes without complications and once it was finished, the introducer was with drawned without reversing heparin and a bandage on the puncture site was performed. The patient was observed for 75 minutes and then was discharged without complications.

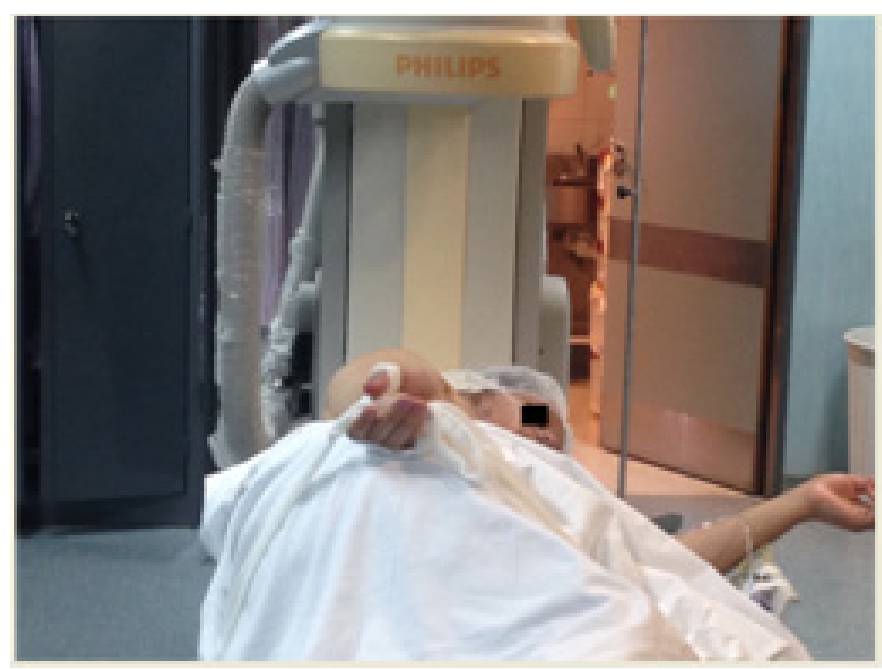

Figure I The patient placed on the table in a left lateral decubitus with the right arm in the supine position on the right side edge of the body and the hand attached with a bandage.
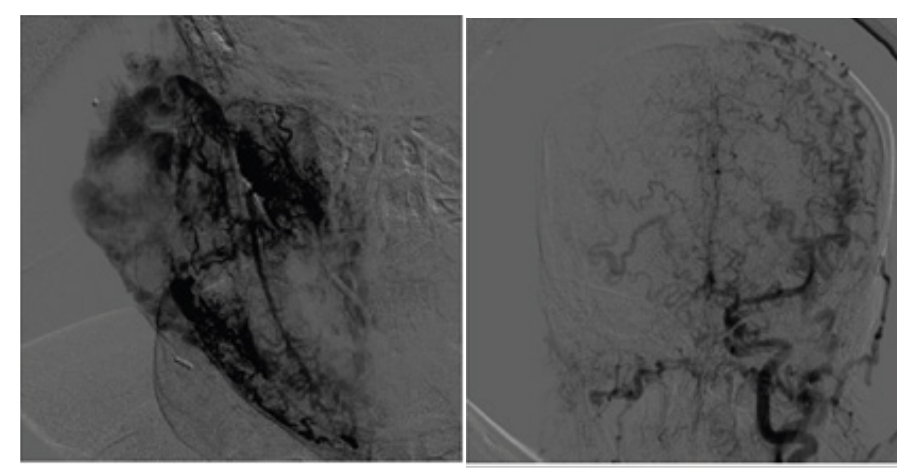

Figure 2 Both carotid arteries were studied. 


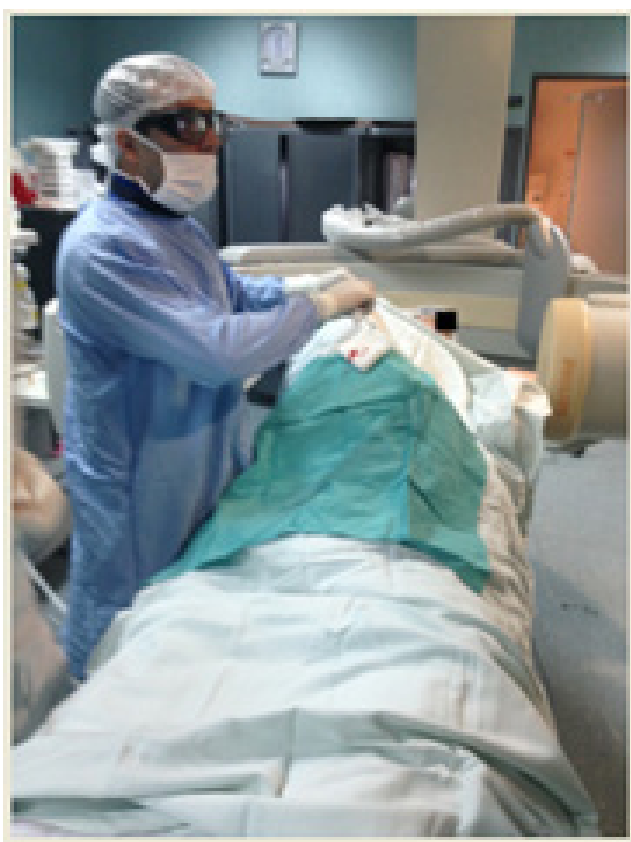

Figure 3 The arch was located perpendicular and in front to the patient.

\section{Discussion}

Transradial approach for cerebral angiography has been described in multiple studies and is the first choice of approach of cerebral angiography in our department because of the increased comfort reported by patients, decreased stay time and complications associated with it. ${ }^{6}$ The technique used was described in other articles and is not part of the interest of this presentation. ${ }^{8,9}$ This case presents the particularity of a patient presenting with profuse bleeding in supine decubitus. The only position that had no bleeding was ventral and lateral. The radial approach is an excellent choice of approach since it is possible puncturing the artery in both the supine and the ventral side. However for selective catheterization of the neck vessels it found it easier to try with the patient in lateral decubitus position and the arc perpendicular equipment to the patient (Figure 2). There is no other description in the literature performance of a cerebral angiography in lateral decubitus position so it seemed important to report this case demonstrating a new utility of the transradial approach.

\section{Conclusion}

Transradial cerebral angiography has many advantages over the femoral route. The possibility of studies in lateral decubitus is a further advantage of this approach. This report constitutes the first case of cerebral angiography in lateral decubitus position.

\section{Acknowledgements}

None.

\section{Conflict of interest}

The author declares no conflict of interest.

\section{References}

1. Campeau L. Percutaneous radial artery approach for coronary angiography. Cathet Cardiovasc Diagn. 1989;16(1):3-7.

2. Kiemeneij F, Laarman G. Transradial artery coronary angioplasty. Am Heart J. 1995;129(1):1-7.

3. Kiemeneij F, Laarman GH, Odekerken D, et al. A randomizedcomparison of percutaneous translumenal coronary angioplastyby the radial, brachial, and femoral approaches: Theaccess study. J Am CollCardiol. 1997;29(6):1269-1275.

4. Cooper CJ, El-Shiekh RA, Cohen DJ, et al. Effect of transradial acces on quality of life and cost of cardiac catheterization: a randomized comparison. Am Heart J. 1999;138(3Pt 1):430-436.

5. Eichhofer J, Horlick E, Ivanov J, et al. Decreased complication rates using the transradial compared to the transfemoral approach in percutaneous coronary intervention in the era of routine stenting and glycoprotein platelet IIb/IIIa inhibitor use: a large single-center experience. Am Heart J. 2008;156(5):864-870.

6. Goland J, Doroszuk G, Garbugino S, et al. Transradial approach to treating endovascular cerebral aneurysms: Case series and technical note. Surg Neurol Int. 2017;8:73.

7. Daou B, Chalouhi N, Tjoumakaris S, et al. Alternative access for endovascular treatment of cerebrovascular diseases. Clin Neurol Neurosurg. 2016;145:89-95.

8. Wu CJ, Hung WC, Chen SM, et al. Feasibility and safety of transradial artery approach for selective cerebral angiography. Catheter Cardiovasc Interv. 2005;66(1):21-26.

9. Kwang WJ, Sung MP, San DK, et al. Is transradial cerebral angiography feasible and safe? A single center's experience. J Korean Neurosurg Soc. 2010;47(5):332-337. 